\title{
NOISE MEASUREMENTS IN SHUNTED, SHORTED, AND FULLY ELECTRODED QUARTZ GAUGES IN THE SATURN PLASMA RADIATION SOURCE X-RAY SIMULATOR ${ }^{1}$
}

\author{
W. H. Barrett, J. I. Greenwoll, C. W. Smith \\ Sandia National Laboratories, Albuquerque, NM 87185-1159 \\ D. E. Johnson, C. F. De La Cruz \\ Ktech Corporation, 901 Pennsylvania NE, Albuquerque, NM 87110
}

\begin{abstract}
This paper describes recent work to improve the measurement of the stress response of materials to intense, short pulses of radiation. When Saturn fires, large prompt electrical noise pulses are induced in stress measurement circuits. The conventional wisdom has been that the shorted guard ring quartz gauge was the only configuration with acceptable prompt signal-to-noise characteristics for stress measurements in this pulsed radiation environment. However, because of abnormal signal distortion, the shorted guard ring gauge is restricted to a maximum stress of about 8 kbars. Below this level, the normal, quantified signal distortion is correctable with analytical deconvolution techniques. The shunted guard ring gauge is acceptable for high fidelity measurements to about $25 \mathrm{kbars}$ with negligible signal distortion. Experiments were conducted on the Saturn sof $\mathrm{x}$-ray source which show that higher fidelity shunted guard ring gauges can successfully measure stress with acceptable induced noise. We also found that a 50-ohm impedance matching resistor at the gauge reduced the prompt noise amplitude and improved the baseline quality of the measurement prior to shock wave arrival.
\end{abstract}

\section{INTRODUCTION}

The Saturn accelerator at the Sandia National Laboratories is a 36 module, high power, variablespectrum, $x$-ray simulation source that can be operated in the bremsstrahlung or plasma radiation source (PRS) modes. For these experiments, Saturn was configured in the PRS mode utilizing argon as the source gas. The total $x$-ray yield from this source is approximately 300 kjoules. Approximately 40 kjoules of this is $\mathrm{K}$-shell atomic line radiation near $3.2 \mathrm{keV}$ in a $20 \mathrm{~ns}$ FWHM pulse.(1), (2) Thin filters (1.2 $\mu \mathrm{m}$-thick polycarbonate with $200 \AA$ of $\mathrm{Al}$ ) were used to eliminate the UV and soft $X$-ray components below $1 \mathrm{keV}$.

Stress measurements which faithfully reproduce the

${ }^{1}$ Work supported by the USDOE under contract DE-AC0494AL85000 state of stress in material samples exposed to this intense, short duration, soft $\mathrm{x}$-ray source are needed to understand material behavior and determine material properties. Prompt electrical noise pulses of several hundred volts are induced in the measurement circuits. Signals of a few volts are typical amplitudes for our experiments. The stress wave transit time through the material separates the prompt noise from the stress signal. However, significant baseline disruption frequently occurs causing uncertainty in arrival times and stress amplitudes. The conventional wisdom has been that the shorted guard ring quartz gauge was the only configuration with acceptable prompt signal-tonoise characteristics for stress measurements at Saturn. (See paper $5 \mathrm{Gl}$ by Montgomery, Graham, and Anderson for a description of the different quartz gauge configurations used in these experiments.) However, because of abnormal signal distortion, the shorted guard ring gauge is restricted to a maximum stress of about 8

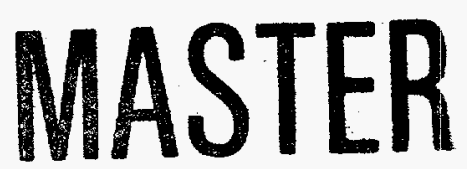

DISTRIBUTION OF THS DOCUMENT IS UNLMMITED Git 


\section{DISCLAIMER}

This report was prepared as an account of work sponsored by an agency of the United States Government. Neither the United States Government nor any agency thereof, nor any of their employees, makes any warranty, express or implied, or assumes any legal liability or responsibility for the accuracy, completeness, or usefulness of any information, apparatus, product, or process disclosed, or represents that its use would not infringe privately owned rights. Reference herein to any specific commercial product, process, or service by trade name, trademark, manufacturer, or otherwise does not necessarily constitute or imply its endorsement, recommendation, or favoring by the United States Government or any agency thereof. The views and opinions of authors expressed herein do not necessarily state or reflect those of the United States Government or any agency thereof. 


\section{DISCLAIMER}

Portions of this document may be illegible in electronic image products. Images are produced from the best available original document. 
fully electroded gauge was more than three times greater than the pulse for the shorted gauge.

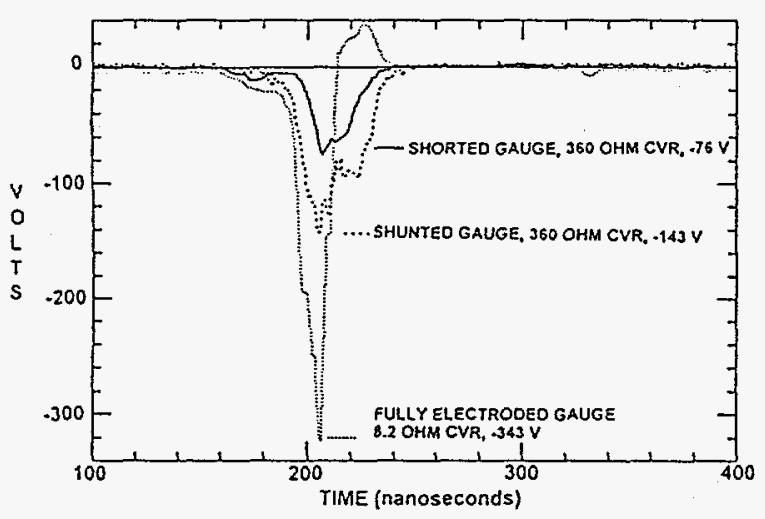

FIGURE 1. Prompt noise comparison, test series 1.

Figure 2 shows the stress waveforms from the recording instruments set for optimum resolution of the stress pulse. From top to bottom, the traces are from the shorted, shunted, and fully electroded gauges. Three typical characteristics of the baselines prior to shock arrival can be seen. The three peaks immediately following the negative prompt noise pulse are visible in all three traces to a different degree. These are probably due to reflections of the prompt noise pulse from small electrical impedance mismatches at connections in or very near the gauge housing. The trace does not return to the baseline prior to shock arrival, probably due to slow amplifier recovery from the three noise peaks. There is a pulse at about $440 \mathrm{~ns}$ (negative for the shorted and shunted gauges, $360 \mathrm{ohm} \mathrm{CVR}$, and positive for the fully electroded gauge, $8.2 \mathrm{ohm} \mathrm{CVR).} \mathrm{One} \mathrm{of} \mathrm{the}$ authors, Smith, traced this to small electrical impedance mismatches at the screen room wall which reflect a small part of the prompt noise pulse. This reflection pulse is then reflected from the non-50 ohm gauge and mixes with the stress signal. A mismatch of a few percent can result in the reflection of a few volts if the noise pulse is a fewv hundred volts, as is the case here.

The response of the shorted and shunted gauges were similar, although the shorted gauges usually had better baseline quality. While results for the fully electroded gauge did not appear very promising we decided to proceed with a more thorough investigation of the low noise quartz gauge design for Saturn PRS experiments.
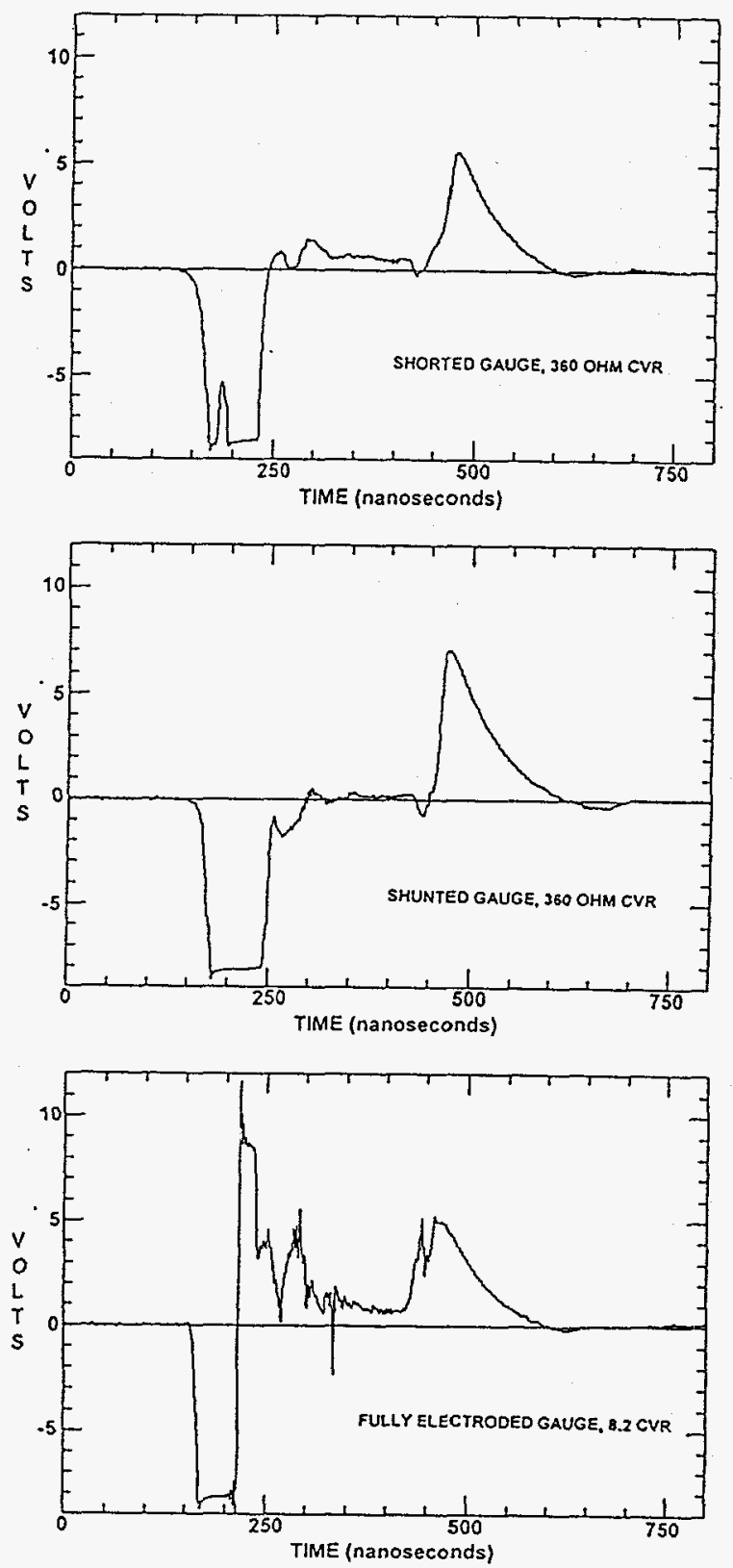

FIGURE 2. Baseline and stress waveform comparison, series 1: top, shorted gauge, $360 \mathrm{ohm}$; middle, shunted gat:ge, $360 \mathrm{ohml}$; bottom, fully electroded gauge, $8.2 \mathrm{ohm}$.

Figure 3 presents typical examples from Test Series 2 and 3 of 50-ohm versus open CVR for the shunted and fully electroded gauges and 50-ohm versus 360-ohms CVR for the shorted gauge. The improvement is obvious. The reflections at the toe of the stress pulse do 
kbars. Below this level, the normal, quantified signal distortion is correctable with analytical deconvolution techniques. The shunted guard ring gauge is valid for high fidelity measurements to about $25 \mathrm{kbars}$ with negligible signal distortion. The fully electroded gauge was proposed for manufacturability and economic reasons.

\section{DESCRIPTION OF EXPERIMENT}

Three series of Saturn shots, beginning in August 1994, were undertaken to determine the feasibility of using shunted and fully electroded gauges in Satum. In Test Series 1, we exposed twelve, 0.76-mm thick PMIMA (polymethyl methacrylate, Polycast UVB) samples mounted on $31.75-\mathrm{mm}$-diameter by $6.35-\mathrm{mm}$ thick quartz gauges. The active area, encompassed by the center electrode, was $12.7 \mathrm{~mm}$ in diameter for the shorted and shunted gauges. The active area for the fully electroded gauge was, of course, the full $31.75 \mathrm{~mm}$. Two identical quartz gauges each of the three designs (shorted guard ring, shunted guard ring, and fully electroded) were fielded on each of two Saturn shots. All gauges were at the same distance from the PRS source. The nominal fluence level was $5 \mathrm{cal} / \mathrm{cm}^{2}$. Therefore, four nominally identical measurements were obtained for each gauge design.

A current viewing resistor (CVR) was installed between the center electrode and the negative (front face) electrode. We chose the resistance value to obtain equal stress signal amplitudes independent of the gauge type. This allowed a direct comparison of signal-tonoise ratio of the different gauges. The CVR value for the shorted and shunted gauges was $360 \mathrm{ohm}$; for the fully electroded, it was $8.2 \mathrm{ohm}$.

The feasibility of using shunted or shorted gauges was successfully demonstrated in Test Series 1. Two followon series of shots, conducted in October and December 1994, were designed to explore the effects on the prompt noise of the choice of the CVR value. In earlier experiments in underground nuclear weapon effects tests, Sandia had demonstrated that the lowest noise was achieved using an impedance matching resistor at the gauge. A 50-ohm resistor at the gauge and at the recording instrument matched the 50 -ohm characteristic impedance of the long ( 500 to $2000 \mathrm{ft}$ ) coaxial signal cable runs. This design minimized reflections of large noise spikes at connectors, attenuators, equalization networks, and the gauge, although the technique reduces the signal by a factor of two. We decided to try the same approach at Saturn. For comparison we also fielded gauges with the CVR value used in the August shots and with no CVR in the gauge, the open or infinite resistance configuration. The latter has been the standard method used to date at Saturn.

On Test Series 2 and 3, we used the same three quartz gauge designs. On Test Series 2, we used identical PMMA material samples. On Test Series 3, we increased the thickness of the PMMA sample to 1.27 $\mathrm{mm}$ in order to increase the time between the prompt noise and the stress signal. For the shunted guard ring gauge, there were a total of seven $50-\mathrm{ohm}$, three 360 ohm, and five open CVR gauges. For the fully electroded gauge, there were a total of five 50 -ohm, three 8.2-ohm and five open CVR gauges. For the shorted guard ring gauges, there were only four 50-ohm gauges.

The data acquisition system consisted of Cujac 141 coax cable from the gauge to the Satum diode vacuum feedthru port (11- to 14-ns long), RF-214 coax cables from the vacuum feedthru port to the J-Box (about 30 ns-long), the permanent $1 / 2$ " heliax cable plant from the J-box to the screen room wall (72-ns long), the recording instruments in the screen room, and the VAX computer controller. We used two each Tektronix SCD1000 flash converters (with $3 / 8$ " heliax cables, 58-ns long) on each gauge to cover the amplitude dynamic range of both the hundreds of volts prompt noise pulse and the several volt stress signal. We also used two each Hewlett-Packard HP-54524A digitizers (with 1/4" heliax cables, 41-ns long) to cover a 4 -ms recording window in order to record several shock reverberations through the samples. All recorders were terminated in $50 \mathrm{ohm}$ at the input.

\section{RESULTS}

Figure 1 shows typical examples of the prompt noise pulses we saw in Test Series 1. The solid line is from the shorted guard ring gauge, the dashed line is from the shunted guard ring gauge, and the dotted line is from the fully electroded gauge. The shorted gauge typically had the lowest amplitude pulse as previous experience had shown. The interesting result is that the shunted gauge pulse was less than $40 \%$ greater, on the average, than the shorted gauge pulse. The prompt noise pulse for the 
not appear in the 50-ohm records. The " 3 " noise peaks are reduced, although not eliminated. The baseline offset is less for most, but not all of the 50-ohm gauges. The longer baseline of the 50 -ohm shorted gauge results from using a thicker PMMA sample on that shot.
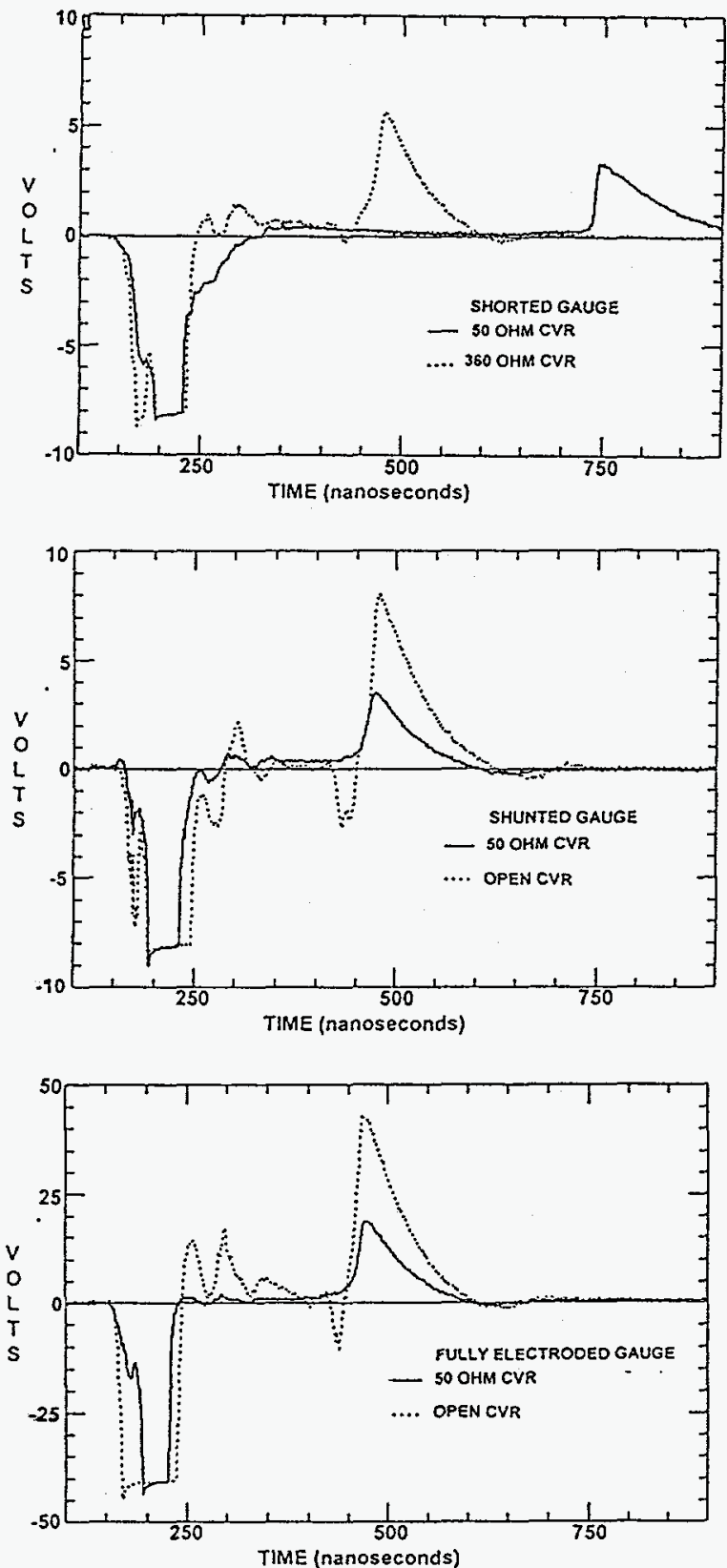

FIGURE 3. High versus $50 \mathrm{ohm}$ CVR comparison: top, shorted gauge, 360 vs $50 \mathrm{ohm}$; middle, shunted, open vs $50 \mathrm{ohm}$; botton, fully electroded, open vs $50 \mathrm{ohm}$.
Table 1 is a summary of the results of all three test series. For the prompt noise and the stress pulse, the numbers given are averages of all the good measurements for that gauge type. The numbers given for the three baseline characteristics are the average of the absolute values for all gauges of that design. A good measurement was when Saturn produced the nominal yield of between approximately 35 and 55 kjoules.

TABLE 1. Summary of results.

\begin{tabular}{|c|c|c|c|c|c|c|}
\hline $\begin{array}{l}\text { Gauge } \\
\text { Type }\end{array}$ & $\begin{array}{l}\text { CVR } \\
\text { Resist. } \\
\text { Ohms } \\
\end{array}$ & $\begin{array}{l}\text { Prompt } \\
\text { Peak } \\
\text { V }\end{array}$ & $\begin{array}{c}\text { "3" } \\
\text { Peaks } \\
\text { V } \\
\end{array}$ & $\begin{array}{c}\text { Baseline } \\
\text { at } 400 \mathrm{~ns} \\
\mathrm{~V}\end{array}$ & $\begin{array}{l}\text { Reflec- } \\
\text { tion } \\
\mathrm{V} \\
\end{array}$ & $\begin{array}{c}\text { Peak } \\
\text { Signal } \\
V\end{array}$ \\
\hline horted & 360 & -82 & 1.16 & 0.19 & 0.46 & 5.2 \\
\hline & 50 & -50 & 0.88 & 0.10 & 0.00 & 3.4 \\
\hline hunted & None & -156 & 2.04 & 0.21 & 2.04 & 8.1 \\
\hline & 360 & -113 & 1.19 & 0.28 & 0.76 & 6.5 \\
\hline & 50 & -131 & 1.11 & 0.18 & 0.00 & 3.8 \\
\hline cully & None & -623 & 29.20 & 4.32 & 20.40 & 43.2 \\
\hline Electro- & 50 & -319 & 3.08 & 0.96 & 0.00 & 19.6 \\
\hline ded & 8.2 & -262 & 29.93 & 0.62 & 2.33 & 4.8 \\
\hline
\end{tabular}

\section{CONCLUSIONS}

We have drawn two major conclusions from our recent quartz gauge work at Saturn. One, the shunted guard ring gauge, which has the highest fidelity, can be used at Saturn with acceptable, although slightly higher, prompt noise response than the normally used shorted guard ring gauge. Two, using a 50-ohm termination resistor at the gauge reduces the prompt noise pulse and, more importantly, significantly reduces the later baseline distortions which can cause serious uncertainty in the stress measurement.

\section{ACKNOWLEDGMENTS}

These experiments could not have been done without the dedication and professional efforts of the Saturn crev.

\section{REFERENCES}

1. SAND 92-2157, "Sandia National Laboratories Radiation Facilities Brochure", UC-9000, August 1993. 2. Spielman, R. B., et. al., "Z-Pinch Experiments on Satum at 30 TW", in AIP Conference Proceedings No. 195 on Dense Z-Pinches, 1989, pp. 3-16. 